Baliatsas, C., Kamp, I. van, Hooiveld, M., Lebret, E., Yzermans, J. The relationship of modern health worries to non-specific physical symptoms and perceived environmental sensitivity: a study combining self-reported and general practice data. Journal of Psychosomatic Research: 7 2015, 79(5), 355-361

\begin{tabular}{|l|l|}
$\begin{array}{l}\text { Postprint } \\
\text { Version }\end{array}$ & 1.0 \\
\hline Journal website & $\underline{\text { http://www.jpsychores.com/article/S0022-3999(15)00541-3/abstract?cc=y= }}=$ \\
\hline Pubmed link & $\underline{\text { http://www.ncbi.nlm.nih.gov/pubmed/26526308 }}$ \\
\hline DOI & $10.1016 / j . j p s y c h o r e s .2015 .09 .004$ \\
\hline
\end{tabular}

This is a NIVEL certified Post Print, more info at http://www.nivel.eu

\title{
The relationship of modern health worries to non- specific physical symptoms and perceived environmental sensitivity: A study combining self- reported and general practice data
}

\author{
CHRISTOS BALIATSAS ${ }^{\mathrm{A}}$ IRENE VAN KAMP ${ }^{\mathrm{B}}$, MARIËTTE HOOIVELD ${ }^{\mathrm{A}}$, ERIK LEBRET $^{\mathrm{B}}$, JORIS \\ YZERMANS $^{\mathrm{A}}$ \\ ${ }^{\text {a }}$ Netherlands Institute for Health Services Research (NIVEL), Utrecht, The Netherlands \\ ${ }^{\mathrm{b}}$ National Institute for Public Health and the Environment (RIVM), Bilthoven, The \\ Netherlands
}

\begin{abstract}
Objective

The present study investigates the association of modern health worries (MHW) with self-reported as well as general practitioner (GP)-registered non-specific physical symptoms (NSPS), medication use, alternative therapy consultations, sleep quality and quality of life. The interrelation between MHW, general environmental sensitivity and the aforementioned outcomes is also explored.

Methods

Self-reported questionnaires and data from electronic medical records from 21 general practices in The Netherlands were combined in a sample of 5933 adult participants.

Results

The majority of the participants reported increased worries about potential health effects from environmental exposures. The highest worry scores were reported by people who perceived themselves as more vulnerable to environmental stressors. After adjustment for socio-demographic characteristics and diagnosed psychiatric morbidity, higher MHW were significantly associated with increased self-reported prevalence and duration of NSPS, symptom-related healthcare utilization, GP-registered NSPS, alternative therapy consultations and lower sleep quality and quality of life. These associations were statistically mediated by perceived environmental sensitivity. No association was observed between worries and GP-registered medication prescriptions.

Conclusion
\end{abstract}


Baliatsas, C., Kamp, I. van, Hooiveld, M., Lebret, E., Yzermans, J. The relationship of modern health worries to non-specific physical symptoms and perceived environmental sensitivity: a study combining self-reported and general practice data. Journal of Psychosomatic Research: 7 2015, 79(5), 355-361

Modern health worries are very common in the general population. They are associated with self-reported as well as clinically defined NSPS and as such might play a key role in the process of developing and maintaining environmental sensitivities and related symptoms. A large cross-cultural longitudinal study would help to determine important aspects such as temporal precedence and stability of MHW and the relevant psychosocial context within which symptomatic conditions occur.

\section{INTRODUCTION}

In recent years, the rapid advances in several domains of human activity such as urbanization, exploitation of energy resources, food production and constant expansion of mobile communication systems have led to substantial gains in living standards, but also introduced potential threats to population's health. Environmental sources resulting from technological development can intersect with adverse health effects and while new types of pollutants emerge [1], associated worries follow [2]. Such concerns are often justified, considering the well-documented harmful effects of a number of pollutants [3], [4] and [5]. Nevertheless, people's worries about a given source can also be in conflict with what research evidence suggests, as in the case of attribution of non-specific physical symptoms (NSPS) to everyday life electromagnetic fields (EMF) [6], [7] and [8]. When it comes to controversial public health issues, such worries may be amplified by the interaction of multiple factors within the societal context, involving scientific uncertainty, political debate and media attention [9], [10] and [11].

Over the past years, the term modern health worries (MHW) has been used predominantly to reflect the individual perception of risk towards environmental agents such as air pollutants, food additives, noise and electromagnetic fields (EMF), as well as contemporary environmental issues such as ozone depletion [12] and [13]. A growing body of studies has shown an association between MHW and several health and behavioral outcomes such as self-reported NSPS, healthcare utilization, use of alternative medicine, health anxiety, somatosensory amplification, depression and lower health-related quality of life [2], [13], [14], [15], [16], [17], [18], [19] and [20]. The exact role though of worries in the context of environmental health has not been settled. In addition, the vast majority of studies assessing MHW as predictor of health outcomes has been exclusively based on self-reported data; the association between worries and clinically defined outcomes such as general practitioner (GP)-registered non-specific/medically unexplained symptoms is yet unknown. In addition, most studies in this field were based on small samples from particular population subgroups, while confounding adjustment was limited. Self-reported sensitivities are often attributed to diverse environmental stressors such as noise, odors, chemical substances and EMF [21], [22] and [23]. Similar to MHW, such subjective environmental sensitivities are associated with more NSPS, poorer perceived health and increased illness behavior particularly related to alternative therapies compared to the broader population [24]. In contrast to sufferers' experiences, the attributed causes are often not supported by scientific evidence [7] and [23], while the reported health complaints are not fully explained by medical or psychiatric morbidity [24]. 
Baliatsas, C., Kamp, I. van, Hooiveld, M., Lebret, E., Yzermans, J. The relationship of modern health worries to non-specific physical symptoms and perceived environmental sensitivity: a study combining self-reported and general practice data. Journal of Psychosomatic Research: 7 2015, 79(5), 355-361

Due to the documented overlap in terms of behavioral and health characteristics and co-occurrence with other idiopathic intolerances, environmental sensitivities may share similar psychophysiological mechanisms, being variants of a broader condition, usually referred to as idiopathic environmental intolerance (IEI) [24], [25] and [26].

MHW seem to be particularly high among people with self-reported sensitivities [27], [28] and [29], while some evidence supports their role as part of a cognitivebehavioral mechanism that leads to IEI and associated symptoms. Bailer et al. [27] found that the association between worries and doctor consultations was explained by IEI-complaints, indicating that increased worries could constitute a risk factor for the development of environmental intolerances. This is in line with the conclusions of a more recent study which showed that NSPS attributed to EMF are more likely to occur in people with higher pre-existing worry levels [30]. However, it is still underinvestigated in the general population to what extent people's MHW are associated with the tendency to perceive themselves as more vulnerable to environmental stressors and what this could indicate in relation to NSPS and other health outcomes.

The present study has three aims, combining GP-registered and self-reported data and taking into account socio-demographic characteristics and diagnosed psychiatric morbidity: 1) To test the association between MHW and self-reported and GPregistered NSPS, medication use, alternative therapy consultations, sleep quality and quality of life 2) To investigate whether higher levels of MHW are associated with higher perceived environmental sensitivity 3 ) In view of the lack of longitudinal data, to test, in an exploratory manner, whether perceived environmental sensitivity statistically mediates the association between MHW and NSPS, medication use, alternative therapy consultations, sleep quality and quality of life.

\section{METHODS}

\section{Participants and procedure}

An epidemiological survey was conducted between January and June 2011, originally aimed to investigate NSPS in relation to everyday life exposure to EMF and psychological factors [31]. Self-reported questionnaires were combined with electronic medical records of NSPS, symptoms and morbidity. Twenty-one general practices across The Netherlands were selected from the primary care database of The Netherlands Institute for Health Services Research (NIVEL). Every Dutch citizen is obliged to be registered at a general practice. Practices within this database register each symptom and diagnosis according to the International Classification of Primary Care (ICPC) [32] using a computerized medical record system [33]. The use of such data for research purposes is performed according to the Dutch Legislation on privacy. The present study was approved by the Dutch Data Protection Authority. Furthermore, the Dutch Medical Ethics Committee decided that an ethical approval was not required according to the Law on Medical Scientific Research (WMO). In total, $\mathrm{n}=13,007$ registered Dutch adult $(\geq 18)$ citizens were invited to participate, which resulted in a sample of $n=5933(46 \%)$.

Additional information regarding the study design and sampling procedure are provided in previous publications [24] and [31]. 
Baliatsas, C., Kamp, I. van, Hooiveld, M., Lebret, E., Yzermans, J. The relationship of modern health worries to non-specific physical symptoms and perceived environmental sensitivity: a study combining self-reported and general practice data. Journal of Psychosomatic Research: 2015, 79(5), 355-361

\section{Self-reported measures}

The self-reported indices used in the present study have been previously validated in the Dutch population.

A 24-item version of the Modern Health Worries (MHW) scale [12] and [14] was used to assess participants' levels of MHW. Answers were scored on a 5-point Likert scale ranging from 1 to 5. A higher score indicates increased MHW. A few items of the original Dutch version of the scale were adapted/simplified due to relevance and national characteristics. More specifically, the item "other environmental pollution" was replaced with "climate change/greenhouse effect" and the item "fluoridation of water" was omitted. Cronbach's alpha for this scale was .95 in the present sample.

To assess perceived environmental sensitivity in the main analyses, an 11-item scale adapted from Stansfeld et al. [34] was used. This list measures subjective sensitivity to various environmental agents/stressors such as noise, light, temperature, materials, scented detergents, smells in general, temperature changes, cold or warm environment and EMF (Cronbach's $\alpha=.82$ ). Answers were formatted on a five-point scale ranging from 0 ("strongly disagree") to 4 ("strongly agree"). A higher total score indicates a higher general sensitivity. In addition, based on this scale, three case definitions were used in the descriptive results, to give an overview of the mean MHW scores of subgroups with specific subjective (hyper)sensitivities. More specifically, participants reporting "absolutely agree" on the corresponding items of noise and chemical sensitivity were considered as hypersensitive to these stressors, while two items were used for the case definition of high EMF sensitivity, following the approach of Baliatsas et al. [24].

Number of NSPS (in the past month), duration of NSPS and related healthcare utilization (in the past year) were assessed using 23 items from the recently validated Symptoms and Perceptions scale [35], representing physical symptoms that are often reported in general practice as unexplained. A higher total score in the corresponding assessment methods (range: 0-23, 0-92 and 0-23 respectively) indicates increased report, duration and symptom-related primary care utilization. For the latter, a dichotomous variable $(\geq 2)$ was used in the analyses.

Sleep quality was measured using a 10-item version of the Sleep Quality Scale [36]. A higher score (range: 0-10) indicates lower subjective quality of sleep.

The 7-item Personal Well-being Index (PWI-A), [37] was used to assess different aspects of quality of life on an 11-point scale. The scale ranges between 0 and 100, with a higher sum score indicating better perceived quality of life.

Information was also obtained on whether respondents consulted a psychologist/psychotherapist and/or an alternative therapist (e.g. homeopathist, acupuncturist, paranormal therapist) within the past year. Additionally, participants were asked whether they used a medication that did not require a doctor prescription. The 12-item version of the General Health Questionnaire (GHQ-12) [38] and [39] was used for a sensitivity analysis to assess psychiatric morbidity. The binary scoring method was used in the present analyses (score range: $0-12$ ). A cut-off point of $\geq 4$ was used to high risk for non-psychotic mental health problems such as anxiety disorders and depression [40]. Finally, information was collected on socio-demographic characteristics (Table 1). 
Baliatsas, C., Kamp, I. van, Hooiveld, M., Lebret, E., Yzermans, J. The relationship of modern health worries to non-specific physical symptoms and perceived environmental sensitivity: a study combining self-reported and general practice data. Journal of Psychosomatic Research: 2015, 79(5), 355-361

\section{[TABLE 1]}

\section{Data from electronic medical records}

The clinical judgment of the general practitioners was based on the concept of "episodes of care" [41]. An episode was labeled as non-specific/medically unexplained in the case of absence of pathological etiology as an explanation for the symptoms, during the year from the survey completion. General practitionerregistered NSPS corresponded with the symptom items from the self-reported questionnaire. When necessary, GP-registered symptoms were clustered, since ICPC codes can reflect different types of the same symptom; "headache", for example, is registered using the codes N01 (headache) and N02 (tension headache). The total prevalence of registered prescriptions within the same timeframe consisting of painkillers, tranquilizers and antidepressants was also obtained, classified based on the Anatomical Therapeutic Chemical Classification system (ATC) [42]. More details regarding the GP-registered outcomes are presented elsewhere [24]. Information was also obtained on diagnosed/GP-registered medical and nonpsychotic psychiatric morbidity based on ICPC-1 (Table 1).

\section{Data analysis}

First, descriptive analyses were performed to provide an overview of the sample characteristics, providing prevalence rates $(\%)$, mean scores with standard deviations (SD) and (Pearson's r) correlation coefficients. In the main analyses, multiple linear and logistic regression models were carried out for the continuous and binary outcomes respectively. To verify the consistency of the results for the symptom number score, analysis was repeated using negative binomial regression [43], given that it can be interpreted also as a count variable. In all regression models, a set of apriori defined covariates was included, such as age, gender, education, foreign background, home ownership status, degree of urbanization and diagnosed (GPregistered) psychiatric morbidity. Unstandardized (B) and standardized ( $\beta$ ) regression coefficients or odds ratios (OR) and $95 \%$ confidence intervals (CIs) were calculated for each examined association. A p of $<0.05$ was considered statistically significant. A sensitivity analysis was also performed, replacing the prevalence of GP-registered psychiatric morbidity with the GHQ-12 cut-off point $(\geq 4)$ to capture cases who may be at risk but had not been presented to the GP during the previous year. In an additional analysis, the continuous variable for MHW was divided into quartiles as in Andersen et al. [17], in order to enhance interpretability of the ORs in relation to the dichotomous outcomes and comparability with previous studies.

To verify whether perceived environmental sensitivity mediates the association between MHW and the examined health outcomes, a series of conditions should hold, based on multiple regression models [44], [45] and [46]: a) there is a significant association between MHW (primary predictor) and the examined outcome $\operatorname{variable(s);b)~there~is~a~significant~association~between~MHW~and~perceived~}$ environmental sensitivity (hypothesized mediator); c) there is a significant association between the hypothesized mediator and the outcome variable(s) (controlling for the primary predictor as well); d) when both the mediator and the independent variable enter the model, the effect size of the previously significant association between the independent variable and the outcome(s) decreases and becomes non-significant. To verify the significance of the mediations tested, the 
Baliatsas, C., Kamp, I. van, Hooiveld, M., Lebret, E., Yzermans, J. The relationship of modern health worries to non-specific physical symptoms and perceived environmental sensitivity: a study combining self-reported and general practice data. Journal of Psychosomatic Research: 7 2015, 79(5), 355-361

Sobel test was additionally used, as a conservative approach which is appropriate for larger samples [46].

Analyses were performed with the statistical software package IBM SPSS Statistics (SPSS Inc. version 19, Chicago IL, USA).

\section{RESULTS}

\section{Non-response and descriptive results}

Results of the non-response analysis and detailed health characteristics of the respondents have been described in previous publications [24], [31] and [35]. In short, participants were slightly younger, more highly educated and with better perceived health, while there was no difference in terms of gender. Table 1 illustrates the distributions for socio-demographic and residential characteristics and lifestyle indicators in the sample. Collinearity diagnostics based on inter-correlations among the independent variables and the variance inflation factor (VIF) demonstrated no risk for multicollinearity.

There was a significant association between MHW and older age $(\mathrm{r}=.26, \mathrm{p} \leq .001)$. In general, small differences in MHW scores were observed in relation to gender (mean women 78.6, SD 19.0 versus men 73.9, SD 18.9, Cohen's $d=.25, p \leq .001$ ), education (mean lower 78.3, SD 20.6, mean higher 74.0, SD 17.8, partial eta-squared $\eta_{\mathrm{p}}^{2}=.01, \mathrm{p} \leq .001$ ), home ownership status (mean rented 77.5, SD 20.3 vs. owned $76.2,18.4$, Cohen's $d=.07, p=.01$ ), foreign background (mean 79.8 SD 19.5 vs. rest of the sample 76.1 SD 19.0, Cohen's $d=.2, \mathrm{p} \leq .001$ ) and degree of urbanization (mean urbanized 79.2, SD 18.4, mean not urbanized 74.0, SD 19.8, $\eta_{\mathrm{p}}^{2}=.01$, $\mathrm{p} \leq .001)$. People with a diagnosed/GP-registered non-psychotic disorder scored somewhat higher on the MHW scale (mean 78.5, SD 19.5 vs. rest of the sample 76.5, 19.1, Cohen's $\mathrm{d}=.1, \mathrm{p}=.04$ ).

As shown in Fig. 1, the highest levels of worries in the sample were reported about hormones in food $(66.5 \%)$, contaminated water $(63.5 \%)$, antibiotics in food $(63.4 \%)$, drug-resistant bacteria (62.9\%) and pesticides in food (61.5\%). The lowest worry rates were related to potential EMF sources $(14.2 \%-22.4 \%)$, vaccination programs $(23 \%)$ and amalgam dental fillings $(23.4 \%)$.

\section{[FIGURE 1]}

People with higher scores on perceived environmental sensitivity reported more MHW ( $\mathrm{r}=.37, \mathrm{p} \leq .001)$. Indicatively, Fig. 2 presents mean values on items of the MHW scale for the total sample and participants with environmental hypersensitivities considered as among the main variants of IEI.

\section{[FIGURE 2]}

\section{Association between MHW and NSPS and healthcare utilization}

Results are summarized in Table 2. All the investigated outcomes, except for registered and unprescribed medication, were significantly associated with higher levels of MHW (Table 2, Model 1). These associations remained robust after the inclusion of GP-registered psychiatric morbidity in the model (Model 2). 
Baliatsas, C., Kamp, I. van, Hooiveld, M., Lebret, E., Yzermans, J. The relationship of modern health worries to non-specific physical symptoms and perceived environmental sensitivity: a study combining self-reported and general practice data. Journal of Psychosomatic Research: 2015, 79(5), 355-361

\section{[TABLE 2]}

Additional multivariate analyses using the GHQ-12 cut-of point of $\geq 4,(21.3 \%)$ instead of prevalence of GP-registered morbidity yielded similar results (data not shown). When the quartile variable for MHW was analyzed in relation to the dichotomous outcomes in Model 2, the strongest associations were observed for the participants of the highest quartile: GP-registered NSPS (OR 1.37, 95\% CI 1.15$1.64, \mathrm{p} \leq .001), \geq 2$ self-reported NSPS presented to the GP (OR 1.24, 95\% CI $1.05-$ $1.47, \mathrm{p}=.01$ ), consulting an alternative therapist (OR 1.95, 95\% CI 1.45-2.62, $\mathrm{p} \leq .001)$.

\section{The mediating role of perceived environmental sensitivity}

After covariate adjustment there was a significant association between MHW and perceived environmental sensitivity (unstandardized regression coefficient $\mathrm{B}=.13$, $95 \%$ CI .12-.14, standardized regression coefficient $\beta=.32, p \leq .001$ ).

When perceived environmental sensitivity entered the regression model as predictor of NSPS and healthcare utilization, the effect size of worries decreased considerably and became non-significant (Table 2, Model 3).

Taking into account the effects of socio-demographic characteristics, diagnosed psychiatric morbidity and MHW, perceived environmental sensitivity was significantly associated with all the examined outcomes. More specifically: number of NSPS $(\mathrm{B}=.13,95 \% \mathrm{CI} .12-.15, \beta=.26, \mathrm{p} \leq .001)$, duration of NSPS $(\mathrm{B}=.38$, $95 \%$ CI .34-.43, $\beta=.24, \mathrm{p} \leq .001)$, sleep quality $(\mathrm{B}=.055,95 \% \mathrm{CI} .045-.065$, $\beta=.16, p \leq .001)$, quality of life $(\mathrm{B}=-.35,95 \% \mathrm{CI} .4--.3, \beta=-.19, \mathrm{p} \leq .001)$, GPregistered NSPS (OR 1.01, 95\% CI 1.003-1.02, $\mathrm{p}=.001$ ), GP-registered medication prescriptions (OR 1.01, 95\% 1.003-1.02, $\mathrm{p}=.01$ ), unprescribed medication (OR $1.02,95 \%$ CI 1.01-1.03, $\mathrm{p} \leq .001), \geq 2$ self-reported NSPS presented to the GP (OR $1.033,95 \%$ CI $1.024-1.04, \mathrm{p} \leq .001)$, consulting an alternative therapist (OR 1.06, $95 \%$ CI $1.05-1.08, \mathrm{p} \leq .001)$.

Overall, the current analyses suggested that the associations between MHW and NSPS, sleep quality, quality of life and alternative therapy consultations were statistically mediated by general perceived environmental sensitivity, which was also confirmed by the Sobel test (Table 2, footnote). Negative binomial regression produced identical results for the outcome "number of self-reported NSPS".

\section{DISCUSSION}

Results from this study showed that MHW are associated with the prevalence and duration of self-reported NSPS, symptom-related healthcare utilization, GPregistered NSPS, alternative therapy consultations and lower sleep quality and quality of life. Participants in the highest worry quartile were almost twice as likely to consult an alternative therapist. Psychiatric morbidity did not seem to account for these associations. No significant association was found with prevalence of medication, registered or unprescribed. Results are generally in line with the existing body of evidence in this field [2], [17], [13], [14], [15], [16], [18], [19] and [20]. Furthermore, a strong association was found between MHW and general perceived environmental sensitivity, with the latter being a statistical mediator of the relation between worries and the examined outcomes in the present analyses. This finding adds to the limited research on the interrelation between MHW, NSPS and environmental intolerances [27], here operationalized as perceived environmental 
Baliatsas, C., Kamp, I. van, Hooiveld, M., Lebret, E., Yzermans, J. The relationship of modern health worries to non-specific physical symptoms and perceived environmental sensitivity: a study combining self-reported and general practice data. Journal of Psychosomatic Research: 7 2015, 79(5), 355-361

sensitivity and not as health complaints attributed to environmental agents as has often been done.

Worries about adverse health effects from environmental exposures were highly prevalent in the sample and especially among people with self-reported environmental sensitivities. As also documented in previous large sample investigations, the most prominent sources of worries were those related to food production, while possible health effects from EMF sources were of less concern [2] and [17]. The level of worries in the present study was in general higher compared to other investigations. A possible explanation lies in the demographic composition of the sample which had a higher mean age compared to previous studies [2] and [14]. Additional explanations for the comparatively higher worry levels are the fact that our study was based on more recent data and possible questionnaire item variations. The pattern of reported worries was generally quite similar between different sensitivity groups and the total sample.

To our knowledge, this is the first time that the association between MHW and clinically defined NSPS is investigated in a large sample, taking into diagnosed psychiatric morbidity and an extensive set of sociodemographic characteristics, together with the mediating role of general perceived sensitivity. We used primary care data that reflect daily life practice and were obtained from a registry system with established reliability [47]. Another strength of the study is that, in a previous stage, an epidemiological risk assessment was performed, showing no convincing evidence for an association between actual EMF exposure and NSPS [31]. This is especially important if we consider that studies investigating the association between MHW and health usually do not take into account the possible effect of physical exposures. The main shortcoming of the present investigation is its cross-sectional design, which does not allow the investigation of temporal precedence. The investigation of causal mediation requires longitudinal data and therefore, mediation analysis in this paper is considered exploratory. Furthermore, the sample was originally recruited for an epidemiological risk assessment and was not representative, which hinders the descriptive generalization of the prevalence of worries. However, the assessment of the role of psychological factors in relation to NSPS attributed to the environment is facilitated within the context of environmental incidents [13], [31] and [48].

MHW are associated with self-reported and registry-based NSPS and healthcare utilization. In addition, they may be a contributing factor in the development of environmental sensitivities, together with other previously documented predisposing factors such worse perceived health, higher distress levels, low work satisfaction and negative affect [27], [30], [49] and [50], while cognitive as well as behavioral aspects seem to have a prominent role [27] and [30]. Considering the large heterogeneity within environmentally sensitive groups in terms of physiological reactions and attributed sources [51] and [52] it should not be ruled out that within the broad environmental sensitivity spectrum, different competing or complementary explanatory mechanisms might apply [53]. For instance, in sensitivities with a hypothesized genetic predisposition such as noise sensitivity [54], worries could also follow self-reported sensitivity to the stressor instead of preceding it.

To determine the direction of the interrelation between MHW, subjective sensitivities, symptomatic effects and related illness behavior and its stability across time, studies using a longitudinal design are needed. Moreover, there is scope for further research on the definition of MHW as a concept, namely on whether it 
Baliatsas, C., Kamp, I. van, Hooiveld, M., Lebret, E., Yzermans, J. The relationship of modern health worries to non-specific physical symptoms and perceived environmental sensitivity: a study combining self-reported and general practice data. Journal of Psychosomatic Research: 2015, 79(5), 355-361

reflects both cognitive and emotional responses to environmental hazards and to what extent it overlaps with general risk perception. Given the constantly emerging technologies such as nanotechnology [55], the assessment of MHW needs to be regularly updated with new corresponding items.

\section{Competing interests statement}

The authors have no competing interests to report.

\section{Acknowledgments}

Data used in the present study were collected within the framework of the project "EMPHASIS" (project number: 85100002), funded by The Netherlands Organization for Health Research and Development (ZonMw). We would like to gratefully acknowledge the cooperation of respondents and GPs. In addition, we thank Petra ten Veen and Elsbeth de Leeuw-Stravers (data management of EMRs) and Dr. Maaike Langelaan and Floor Borlée for their feedback on the manuscript. The study sponsor had no involvement in study design, collection, analysis, writing and interpretation of the data and in the decision to submit the study for publication.

\section{REFERENCES}

[1] M. Gavrilescu, K. Demnerová, J. Aamand, S. Agathos, F. Fava, Emerging pollutants in the environment: present and future challenges in biomonitoring, ecological risks and bioremediation, New Biotechnol. 32 (2015) 147-156.

[2] W. Rief, H. Glaesmer, V. Baehr, et al., The relationship of modern health worries to depression, symptom reporting and quality of life in a general population survey, J. Psychosom. Res. 72 (2012) 318-320.

[3] World Health Organization, Global Health Risks: Mortality and Burden of Disease Attributable to Selected Major Risks, World Health Organization, Geneva, 2009.

[4] G. Damato, L. Cecchi,M. D'Amato, G. Liccardi, Urban air pollution and climate change as environmental risk factors of respiratory allergy: an update, J. Investig. Allergol.

Clin. Immunol. 20 (2010) 95-102.

[5] D. Gee, P. Grandjean, S.F. Hansen, S.V.D. Hove, M. MacGarvin, J. Martin, et al., Late Lessons from Early Warnings: Science, Precaution, Innovation, EEA (European Environment Agency), Luxembourg, 2013.

[6] G.J. Rubin, R. Nieto-Hernandez, S. Wessely, Idiopathic environmental intolerance attributed to electromagnetic fields (formerly 'electromagnetic hypersensitivity'): an updated systematic review of provocation studies, Bioelectromagnetics 31 (2010) 1-11.

[7] C. Augner, T. Gnambs, R. Winker, A. Barth, Acute effects of electromagnetic fields emitted by GSM mobile phones on subjective well-being and physiological reactions: a meta-analysis, Sci. Total Environ. 424 (2012) 11-15.

[8] C. Baliatsas, I. van Kamp, J. Bolte, M. Schipper, J. Yzermans, E. Lebret, Non-specific physical symptoms and electromagnetic field exposure in the general population: can we get more specific? A systematic review, Environ. Int. 41 (2012) 15-28.

[9] C.C. Engel, J.A. Adkins, N.C. David, Caring formedically unexplained physical symptoms after toxic environmental exposures: effects of contested causation, Environ. Health Perspect. 110 (2002) 641-647.

[10] J.X. Kasperson, R.E. Kasperson, N. Pidgeon, P. Slovic, The social amplification of risk: Assessing fifteen years of research and theory, in: N. Pidgeon, R.E. Kasperson, P.

Slovic (Eds.), The Social Amplification of Risk, University Press, Cambridge 2003, pp. 1346.

[11] B. Eldridge-Thomas, G.J. Rubin, Idiopathic environmental intolerance attributed to electromagnetic fields: a content analysis of British newspaper reports, PLoS One 8 (2013), e65713.

[12] K.J. Petrie, B. Sivertsen, M. Hysing, E. Broadbent, R. Moss-Morris, H.R. Eriksen, Thoroughly modern worries: the relationship of worries about modernity to reported symptoms, health and medical care utilization, J. Psychosom. Res. 51 (2001) 395-401. 
Baliatsas, C., Kamp, I. van, Hooiveld, M., Lebret, E., Yzermans, J. The relationship of modern health worries to non-specific physical symptoms and perceived environmental sensitivity: a study combining self-reported and general practice data. Journal of Psychosomatic Research: 2015, 79(5), 355-361

[13] K.J. Petrie, E. Broadbent, N. Kley, R. Moss-Morris, R. Horne, W. Rief, Worries about modernity predict symptom complaints after environmental pesticide spraying, Psychosom. Med. 67 (2005) 778-782.

[14] A.A. Kaptein, D.I. Helder, W.C. Kleijn, W. Rief, R. Moss-Morris, K.J. Petrie, Modern health worries in medical students, J. Psychosom. Res. 58 (2005) 453-457.

[15] K.B. Filipkowski, J.M. Smyth, A.M. Rutchick, A.M. Santuzzi, M. Adya, K.J. Petrie, et al., Do healthy people worry?Modern health worries, subjective health complaints, perceived health, and health care utilization, Int. J. Behav. Med. 17 (2010) 182-188.

[16] F. Köteles, E. Bárány, P. Varsányi, G. Bárdos, Are modern health worries associated with somatosensory amplification, environmental attribution style, and commitment to complementary and alternative medicine? Scand. J. Psychol. 53 (2012) 144-149.

[17] J. Andersen, J. Jensen, Modern health worries and visits to the general practitioner in a general population sample: an 18-month follow-up study, J. Psychosom. Res. 73 (2012) 264-267.

[18] A. Freyler, Z. Kohegyi, F. Koteles, G. Kokonyei, G. Bardos, Modern health worries, subjective somatic symptoms, somatosensory amplification, and health anxiety in adolescents, J. Health Psychol. 18 (2013) 773-781.

[19] F. Köteles, P. Simor, Modern health worries, somatosensory amplification and subjective symptoms: a longitudinal study, Int. J. Behav. Med. 20 (2013) 38-41.

[20] A.M. Indregard, C.M. Ihlebæk, H.R. Eriksen,Modern health worries, subjective health complaints, health care utilization, and sick leave in theNorwegianworking population, Int. J. Behav. Med. 20 (2013) 371-377.

[21] R. Kreutzer, Idiopathic environmental intolerance: case definition issues, Occup. Med. 15 (2000) 511-517.

[22] M. Lacour, T. Zunder, K. Schmidtke, P. Vaith, C. Scheidt, Multiple chemical sensitivity syndrome (MCS) - suggestions for an extension of the US MCS-case definition, Int.

J. Hyg. Environ. Health 208 (2005) 141-151.

[23] J. Das-Munshi, G.J. Rubin, S. Wessely, Multiple chemical sensitivities: a systematic review of provocation studies, J. Allergy Clin. Immunol. 118 (2006) 1257-1264.

[24] C. Baliatsas, I. Van Kamp, M. Hooiveld, J. Yzermans, E. Lebret, Comparing non-specific physical symptoms in environmentally sensitive patients: prevalence, duration, functional status and illness behavior, J. Psychosom. Res. 76 (2014) 405-413.

[25] M. Heinonen-Guzejev, M. Koskenvuo, H. Mussalo-Rauhamaa, H.S. Vuorinen, K. Heikkilä, J. Kaprio, Noise Sensitivity and Multiple Chemical Sensitivity - Similarities and Differences. Proceedings Internoise, 2013.

[26] E. Palmquist, A.S. Claeson, G. Neely, B. Stenberg, S. Nordin, Overlap in prevalence between various types of environmental intolerance, Int. J. Hyg. Environ. Health 217 (2013) 427-434.

[27] J. Bailer, M. Witthöft, F. Rist, Modern health worries and idiopathic environmental intolerance, J. Psychosom. Res. 65 (2008) 425-433.

[28] G.J. Rubin, A.J. Cleare, S. Wessely, Psychological factors associated with self-reported sensitivity to mobile phones, J. Psychosom. Res. 64 (2008) 1-9.

[29] N. Lind, M. Nordin, E. Palmquist, S. Nordin, Psychological distress in asthma and allergy: the Västerbotten environmental health study, Psychol. Health Med. 19 (2014) 316323.

[30] M. Witthöft, G.J. Rubin, Are media warnings about the adverse health effects of modern life self-fulfilling? An experimental study on idiopathic environmental intolerance attributed to electromagnetic fields (IEI-EMF), J. Psychosom. Res. 74 (2013) 206-212.

[31] C. Baliatsas, J. Bolte, J. Yzermans, G. Kelfkens, M. Hooiveld, E. Lebret, I. van Kamp, Actual and perceived exposure to electromagnetic fields and non-specific physical symptoms: An epidemiological study based on self-reported data and electronic medical records, Int. J. Hyg. Environ. Health 218 (2015) 331-344.

[32] H. Lamberts,M.Wood, International Classification of Primary Care, Oxford University Press, Oxford, 1987.

[33] I. Stirbu-Wagner, S.A. Dorsman, S. Visscher, R. Davids, J.V. Gravestein, H. Abrahamse, et al., The Netherlands Information Network of General Practice. Facts and Numbers in Primary Care [in Dutch]. Utrecht/Nijmegen: NIVEL/IQ, 2010 ([http://www.linh.nl]). 
Baliatsas, C., Kamp, I. van, Hooiveld, M., Lebret, E., Yzermans, J. The relationship of modern health worries to non-specific physical symptoms and perceived environmental sensitivity: a study combining self-reported and general practice data. Journal of Psychosomatic Research: 2015, 79(5), 355-361

[34] S.A. Stansfeld, C.R. Clark, L.M. Jenkins, A. Tarnopolsky, Sensitivity to noise in a community sample: measurement of psychiatry disorder and personality, Psychol. Med. 15 (1985) 243-254.

[35] J. Yzermans, C. Baliatsas, S.VanDulmen, I. VanKamp, Assessingnon-specific symptoms in epidemiological studies: development and validation of the symptoms and perceptions (SaP) questionnaire, Int. J. Hyg. Environ. Health (2015) (in press).

[36] P. Visser, W.F. Hofman, A. Kumar, R. Cluydts, I.P.F. Diana, P. De Marchant, et al., Sleep and mood: measuring the sleep quality, in: R.G. Priest, A. Pletscher, J. Ward (Eds.), Sleep Research, Springer, Netherlands 1978, pp. 135-145.

[37] International Well-being Group, Personal Wellbeing Index - Adult (PWI-A), Fourth edition Australian Centre on Quality of Life, Deakin University, Melbourne, 2006 (http://www.deakin.edu.au/research/acqol/instruments/wellbeing-index/ pwi-adultenglish.pdf).

[38] D.P. Goldberg, The Detection of Psychiatric Illness by Questionnaire. Maudsley Monograph no. 21, Oxford University Press, Oxford, 1973.

[39] M.W.J. Koeter, J. Ormel, General Health Questionnaire, Nederlandse Bewerking Handleiding [General Health Questionnaire, Dutch Version Manual], Swets \& Zeitlinger, Lisse, 1991.

[40] B. Schreuders, H. van Marwijk, J. Smit, F. Rijmen, W. Stalman, P. van Oppen, Primary care patients with mental health problems: outcome of a randomised clinical trial, $\mathrm{Br}$. J. Gen. Pract. 57 (2009) 886-891.

[41] WONCA Classification committee, An international glossary for general/family practice, Fam. Pract. 12 (1995) 341-369.

[42] WHO, Guidelines for ATC Classification and DDD Assignment, WHO Collaborating Centre for Drug Statistics Methodology, Oslo, 2003.

[43] A.C. Cameron, P.K. Trivedi, Regression Analysis of CountData, 53, Cambridge University Press, Cambridge, UK, 2013.

[44] R.M. Baron, D.A. Kenny, The moderator-mediator variable distinction in social psychological research: conceptual, strategic, and statistical considerations, J.

Pers. Soc. Psychol. 51 (1986) 1173-1182.

[45] D.P. MacKinnon, A.J. Fairchild, M.S. Fritz, Mediation analysis, Annu. Rev. Psychol. 58 (2007) 593-14.

[46] A.F. Hayes, Introduction to Mediation, Moderation, and Conditional Process Analysis : a Regression Based Approach, The Guilford Press, 2013.

[47] I.M. Okkes, S.K. Oskam, H. Lamberts, The probability of specific diagnoses forpatients presenting with common symptoms to Dutch family physicians, J. Fam. Pract. 51 (2002) 31-36.

[48] B. van den Berg, Physical Symptoms That are Frequently Unexplained Among Survivors of the Enschede Fireworks Disaster(Doctoral Dissertation) Utrecht University, 2007.

[49] F. Eek, B. Karlson, K. Osterberg, P.O. Ostergren, Factors associated with prospective development of environmental annoyance, J. Psychosom. Res. 69 (2010) 9-15.

[50] S. Skovbjerg, K.B. Christensen, J.F. Ebstrup, A. Linneberg, R. Zachariae, J. Elberling, Negative affect is associated with development and persistence of chemical intolerance: a prospective population-based study, J. Psychosom. Res. 78 (2015) 509-514.

[51] C. Baliatsas, I. van Kamp, E. Lebret, G.J. Rubin, Idiopathic environmental intolerance attributed to electromagnetic fields (IEI-EMF): a systematic review of identifying criteria, BMC Public Health 12 (2012) 643.

[52] A. Tuengler, L. von Klitzing, Hypothesis on how to measure electromagnetic hypersensitivity, Electromagn. Biol. Med. 32 (2013) 281-290.

[53] I. van Kamp, E. van Kempen, C. Baliatsas, D. Houthuijs, Proceedings Internoise, Mental Health as Context Rather Than Health Outcome of Noise: Competing Hypotheses Regarding the Role of Sensitivity, Perceived Soundscapes and Restoration, 2013. [54] M. Heinonen-Guzejev, H.S. Vuorinen, H. Mussalo-Rauhamaa, K. Heikkila, M. Koskenvuo, J. Kaprio, Genetic component of noise sensitivity, Twin Res. Hum. Genet. 8 (2005) 245-249. 
Baliatsas, C., Kamp, I. van, Hooiveld, M., Lebret, E., Yzermans, J. The relationship of modern health worries to non-specific physical symptoms and perceived environmental sensitivity: a study combining self-reported and general practice data. Journal of Psychosomatic Research: 7 2015, 79(5), 355-361

[55] N. Pidgeon, B. Harthorn, T. Satterfield, Nanotechnology risk perceptions and nivel communication: emerging technologies, emerging challenges, Risk Anal. 31 (2011) 16941700. 
Baliatsas, C., Kamp, I. van, Hooiveld, M., Lebret, E., Yzermans, J. The relationship of modern health worries to non-specific physical symptoms and perceived environmental sensitivity: a study combining self-reported and general practice data. Journal of Psychosomatic Research: 7 2015, 79(5), 355-361

\section{TABLES AND FIGURES}

\section{Table 1}

Overview of main sample characteristics.

\begin{tabular}{|c|c|c|}
\hline Characteristic & $\mathrm{N}=5933$ & Missing data ${ }^{a}(\%)$ \\
\hline Mean age (SD) & $52.2(17.3)$ & \\
\hline Female gender (\%) & 58.4 & \\
\hline Education ${ }^{\mathrm{b}}(\%)$ & & 4.1 \\
\hline Lower & 24.0 & \\
\hline Middle & 44.3 & \\
\hline Higher & 31.6 & \\
\hline Foreign ethnic background (\%) & 12.6 & 1.6 \\
\hline Home ownership status (\%) & & 1.0 \\
\hline Owned & 65.3 & \\
\hline Rented & 34.7 & \\
\hline \multicolumn{3}{|l|}{ Degree of urbanization (\%) } \\
\hline Extremely urbanized & 22.9 & \\
\hline Strongly urbanized & 24.6 & \\
\hline Moderately urbanized & 16.3 & \\
\hline Hardly urbanized & 18.7 & \\
\hline Not urbanized & 17.6 & \\
\hline \multicolumn{3}{|l|}{ GP-registered psychiatric morbidity (\%) } \\
\hline Anxiety (ICPC codes: P01, P74) & 2.5 & \\
\hline Depression (P03, P76) & 3.3 & \\
\hline Somatization disorder (P75) & .2 & \\
\hline Neurasthenia (P78) & 1.0 & \\
\hline Phobia/compulsive disorder (P79) & .2 & \\
\hline Personality disorder (P80) & .4 & \\
\hline GP-registered NSPS (\%) & 36.5 & \\
\hline \multicolumn{3}{|l|}{ GP-registered medication prescriptions (\%) } \\
\hline Painkillers & 20.6 & \\
\hline Benzodiazepines & 10.4 & \\
\hline Antidepressants & 7.9 & \\
\hline Unprescribed medication (\%) & 50.5 & \\
\hline \multicolumn{3}{|l|}{ Mean score of self-reported outcomes (SD) } \\
\hline Number of NSPS (in the past month) & $5.3(4.0)$ & 5.9 \\
\hline Duration of NSPS & $12.8(12.5)$ & 7.4 \\
\hline (Low) sleep quality & $2.3(2.6)$ & 8.1 \\
\hline Quality of life & $74.5(14.2)$ & 3.5 \\
\hline $\begin{array}{l}\geq 2 \text { self-reported NSPS presented to the GP (in the } \\
\text { past year) (\%) }\end{array}$ & 33.8 & 2.6 \\
\hline Consulting a psychologist/psychotherapist (\%) & 11.1 & 2.8 \\
\hline Consulting an alternative therapist (\%) & 8.6 & 3.4 \\
\hline MHW score (SD) & $76.6(19.1)$ & 2.5 \\
\hline Perceived environmental sensitivity score (SD) & $20.9(7.8)$ & 2.7 \\
\hline
\end{tabular}

Abbreviations: SD, Standard deviation; MHW, Modern health worries.

a No missing data for age, gender, degree of urbanization and GP-registered data.

b Lower: No education or primary school or lower secondary education; Middle: Intermediate vocational or intermediate general secondary or higher general secondary education; Higher: Higher vocational or university education. 
Baliatsas, C., Kamp, I. van, Hooiveld, M., Lebret, E., Yzermans, J. The relationship of modern health worries to non-specific physical symptoms and perceived environmental sensitivity: a study combining self-reported and general practice data. Journal of Psychosomatic Research: 7 2015, 79(5), 355-361

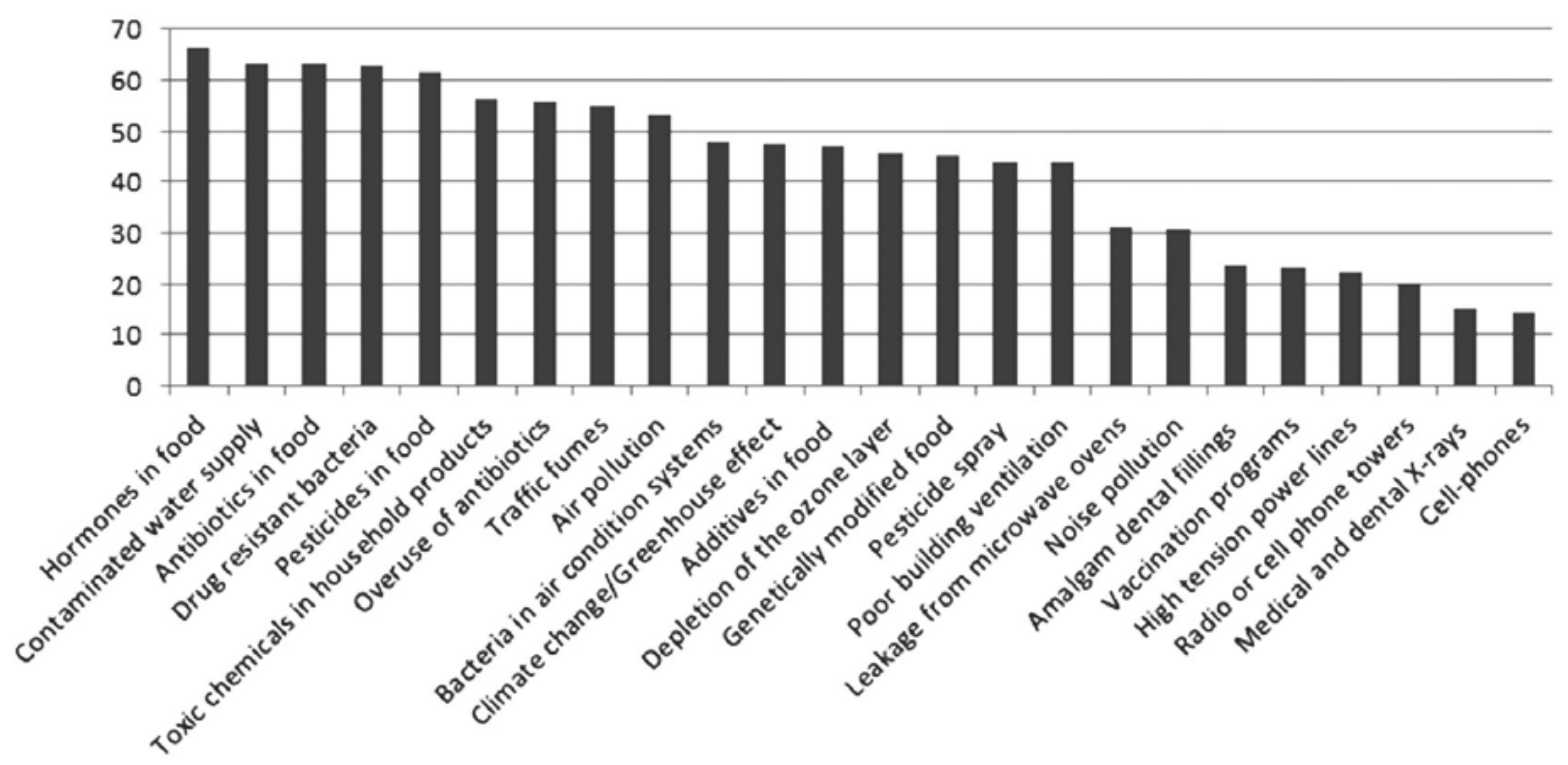

Fig. 1. Percentage (\%) of "high" or "extremely high" concern about the effects of environmental exposures on health.

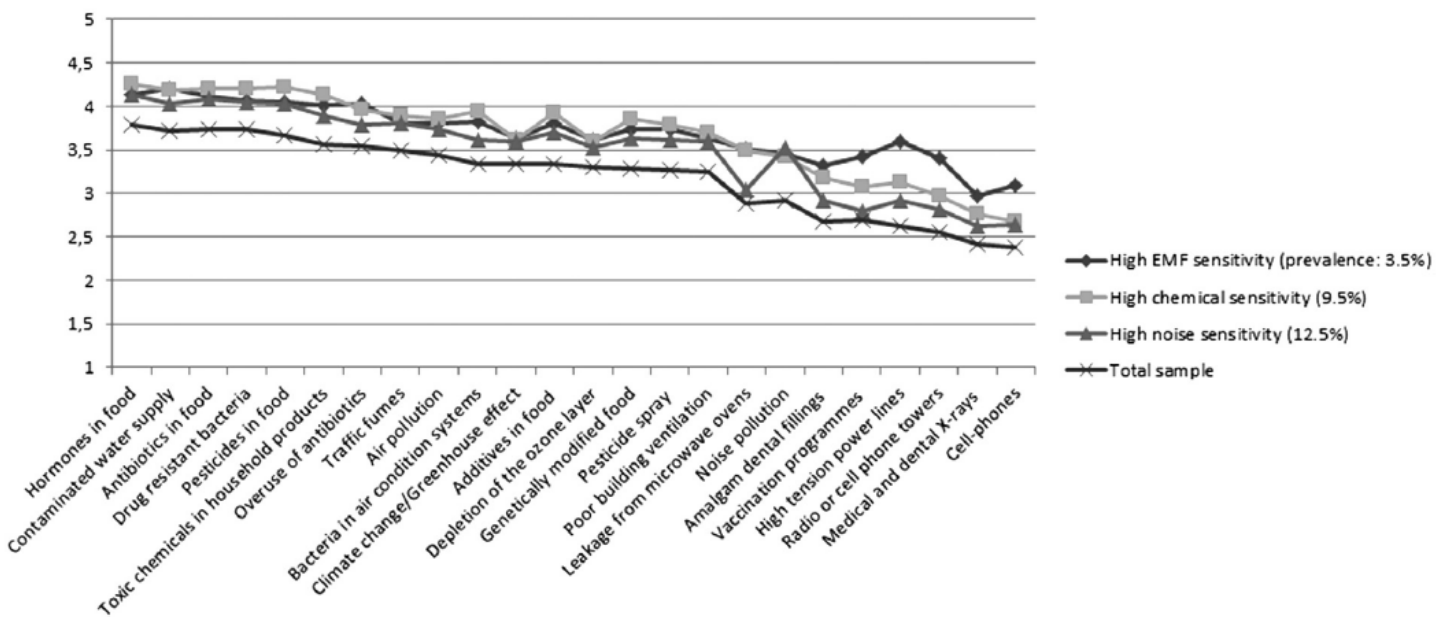

Fig. 2. Mean score on each item of the MHW scale ( 1 = no concern, 5 = extreme concern) for the total sample and people with high subjective sensitivity to different environmental agents. 
Baliatsas, C., Kamp, I. van, Hooiveld, M., Lebret, E., Yzermans, J. The relationship of modern health worries to non-specific physical symptoms and perceived environmental sensitivity: a study combining self-reported and general practice data. Journal of Psychosomatic Research: 7 2015, 79(5), 355-361

Table 2

Regression coefficients and odds ratios of the association between MHW and NSPS, medication and healthcare utilization (Model 1-2) and the mediating role of perceived environmental sensitivity (Model 3).

\begin{tabular}{|c|c|c|c|}
\hline & Model $1^{\text {a }}$ & Model $2^{\mathrm{b}}$ & Model $3^{c}$ \\
\hline \multicolumn{4}{|c|}{ Unstandardized ( $95 \% \mathrm{Cl})$ \& standardized $(\beta)$ regression coefficient } \\
\hline Number of self-reported NSPS & $.02(.014$ to .025$), \beta=.09^{* *}$ & $.02(.013$ to .025$), \beta=.09^{* *}$ & $.001(-.004$ to .01$), \beta=.006^{51}$ \\
\hline Duration of self-reported NSPS & $.06(.04$ to .076$), \beta=.09^{* *}$ & $.055(.04-.073), \beta=.085^{* *}$ & $.004(-.015$ to .02$), \beta=.006^{\mathrm{s2}}$ \\
\hline Sleep quality & $.006(.002$ to .01$), \beta=.044^{*}$ & $.006(.002$ to .01$), \beta=.04^{*}$ & $-.001(-.005$ to .003$), \beta=-.01^{\mathrm{s} 3}$ \\
\hline Quality of life & $-.045(-.065$ to -.025$), \beta=-.06^{* *}$ & $-.044(-.063$ to -.024$), \beta=-.06^{* *}$ & $.002(-.02$ to .023$), \beta=.003^{54}$ \\
\hline \multicolumn{4}{|l|}{ OR $(95 \% \mathrm{Cl})$} \\
\hline GP-registered NSPS & $1.004(1.001-1.01)^{\top}$ & $1.003(1.00-1.01)^{\top}$ & $1.002(.99-1.006)^{\mathrm{s5}}$ \\
\hline GP-registered medication prescriptions & $1.001(1.00-1.004)$ & $1.00(.99-1.004)$ & N.A \\
\hline Unprescribed medication & $1.00(.99-1.004)$ & $1.00(.99-1.004)$ & N.A \\
\hline$\geq 2$ self-reported NSPS presented to the GP & $1.006(1.003-1.01)^{* *}$ & $1.006(1.003-1.01)^{* *}$ & $1.002(.99-1.005)^{\mathrm{s} 6}$ \\
\hline Consulting an alternative therapist & $1.015(1.01-1.02)^{* *}$ & $1.014(1.01-1.02)^{* *}$ & $1.005(.99-1.01)^{57}$ \\
\hline
\end{tabular}

Abbreviations: OR, odds ratio; Cl, confidence interval; N.A, not applicable due to the absence of mediation.

a Adjusted for age, gender, education, foreign background, home ownership status, degree of urbanization, GP-registered psychiatric morbidity.

b Model 1 adjusted for diagnosed (GP-registered) psychiatric morbidity.

${ }^{c}$ Model 2 adjusted for perceived environmental sensitivity.

$s 1$ Sobel test for mediation $\mathrm{z}=14.61, \mathrm{p} \leq .001$.

$\mathrm{s} 2 \mathrm{z}=13.8, \mathrm{p} \leq .001$
$\mathrm{~s} 3 \mathrm{z}=9.88, \mathrm{p} \leq .001$

s4 $\mathrm{z}=-11.97, \mathrm{p} \leq .001$.

$\mathrm{ss}^{\mathrm{z}} \mathrm{z}=2.7, \mathrm{p}=.007$.

s6 $\mathrm{z}=7.15, \mathrm{p} \leq .001$.

s7 $\mathrm{z}=7.67, \mathrm{p} \leq .001$.

T $\mathrm{p}<.05$.

$\mathrm{p}<.05$
$\mathrm{p}<.01$

${ }^{* *} \mathrm{p}<.001$. 